\title{
Neuroticism in patients with psoriasis vulgaris
}

\author{
Blyta $\mathrm{Y}^{*}$ and Ahmeti $\mathrm{N}^{2}$ \\ ${ }^{1}$ Department of Dermatology, University Clinical Center of Kosovo, Pristina, Kosovo \\ ${ }^{2}$ Beauty Academy “ Dermo-estetica” Pristina, Kosovo
}

\begin{abstract}
Introduction and objective: Dermatological patients present significantly more psychological disturbances of various types than the general population. The aim of this study was to analyze neurotic tendencies in psoriasis patients.

Material and methods: The study included a selection of sixty patients with different forms of psoriasis stationary treated in Department of Dermatology. The control group consisted from group 60 healthy persons. All patients underwent standardized structured inventory.

Results: Inventory analysis confirmed presence of neuroticism in $43.3 \%$ of cases which shows significant statistical difference comparing with control group where neuroticism is present in only $10 \%$ of cases.

Conclusion: This study confirms the correlation of psoriasis vulgar with neurotic tendencies. The discovery of this relationship is very important because the presence neurotic tendencies aggravate psoriasis clinical feature with feeble response to specific treatment.
\end{abstract}

\section{Introduction}

Psoriasis is a frequent chronic, genetically determined, immunological, inflammatory and hyperproliferative skin disease of unpredictable clinical evolution. Most frequent skin changes are limited eritemo-sqvamoze lesions different in shape and size. Nails are often attacked while joints changes may appear in 5-7\% of patients with psoriasis [1].

Morbidity ranges from $1-2 \%$ of the total population. Its prevalence varies depending on geographic region. The disease occurs in both sexes equally. Psoriasis may start at any age, although the first manifestation in early childhood and old age of is rare [2].

Psoriasis is a disease with hereditary polygenetic predisposition, whereas exogenous and endogenous factors, may initiate hereditary mechanisms of transformation of clinical latent form of genotype psoriasis in manifested fenotype psoriasis [3]. There are two types of psoriasis: eruptive type featured with small lesions called guttata form, similar with eczematous lesions and chronic plaque type observed in most patients. This form of psoriasis, such lies for months and years and changes very slowly.

Psoriasis is associated more frequently with hypertension, chronic lumbar syndrome, diabetes and myocardial infarction.

Literature gives cases of psoriasis in association with anxiety, depression or other neurotic disorders. Psoriasis is a chronic disease associated with significant physical and psychological morbidity [4]. Psoriasis is a chronic disease that may have significant psychological and social impact in a patient's life. For patient, psoriasis can be much more than "just a skin disease $[5,6]$.

\section{Objective}

The purpose of this paper is to determine neuroticism tendencies in patients with psoriasis.

\section{Material and methods}

All patients underwent standardized structured inventory MMPI201 test (Minnesota Multiphasic Personality Inventory).

MMPI is multidimensional personality inventory which consists of ten clinical scales and four control levels. It is a psychological test which assesses personality traits and psychopathology.

MMPI-201 personality test underwent 60 cases with psoriasis (36 males and 24 females) hospitalized in department of dermatology, Pristina from January 2009 until December 2011. Inclusive criteria have been cases with various forms of psoriasis clinically diagnosed ore in some cases pathohystologicaly. Exclusion criteria were cases with psoriasis associated with other dermatoses, age under land over 17 and over 70 years and patients who refused interview or completing the questionnaire. Based on history and standardized personality inventory personality tendencies in patients with psoriasis were determine.

Same personality inventory testing was performed in control group, which consisted of 60 healthy persons (male 29 and female 31). Statistical significance was determined with $\mathrm{x}^{2}$ and Fisher test. The difference is significant if $\mathrm{P}<0.05$.

\section{Results}

Results showed that out of 60 patients with psoriasis to who underwent the psychological testing neuroticism is detected in 26 cases or $43.3 \%$. Women structure with neuroticism has been much

Correspondence to: Blyta Y, Department of Dermatology, University Clinical Center of Kosovo, Pristina, Kosovo; E-mail: ymranblyta@gmail.com

Key words: psoriasis, neuroticism

Received: December 10, 2014; Accepted: January 14, 2015; Published: January 16,2015 
greater than men (women $62.5 \%$ vs. men $30.6 \%$ ) significant statistical difference $\left(\mathrm{x}^{2}=4.75, \mathrm{P}=0.029, \mathrm{P}<0,05\right)$ (Table 1$)$.

From 60 persons of control group who underwent psychological testing neuroticism was is identified in 6 cases or $10.0 \%$. All cases with neuroticism were woman significant statistical difference (Fisher test, $\mathrm{P}=0.0242, \mathrm{P}<0: 05)($ Table 2$)$

Significant statistical difference $(\mathrm{p}<0.01)$ with neuroticism was found between groups and sexes (Figure l).

\section{Comparison of tendencies according to groups}

Anxiety was found in $55.0 \%$ of cases in the experimental group and $23.3 \%$ of cases in the control group, significant statistical difference $(\mathrm{P}<0.01)$. Depression occurred in $26.7 \%$ of cases in the experimental group and $6.7 \%$ of cases in the control group significant statistical difference $(\mathrm{P}<0.01)$. Hypochondriasis occurred in $36.7 \%$ of cases in the experimental group and $6.7 \%$ of cases in the control group, significant statistical difference $(\mathrm{P}<0.01)$. Phobias occurred in $10.0 \%$ of cases in the experimental group and $6.7 \%$ of cases in the control group without significant statistical difference $(\mathrm{P}>0.05)$. Impulsive aggressive tendencies occurred in $21.7 \%$ of cases in the experimental group and $1.7 \%$ of cases in the control group with significant statistical difference $(\mathrm{P}<0.01)$ (Table 3 and Figure 2).

MMPI testing showed significant statistical difference between the cases with neuroticism by groups and gender, and according to neuroticism trends, with the exception of the tendency for phobia.

Table 1. Psychological test results in psoriasis group

\begin{tabular}{|c|c|c|c|}
\hline \multirow{2}{*}{ Gender } & \multirow{2}{*}{ Total } & \multicolumn{2}{|c|}{ With neuroticism } \\
\cline { 2 - 4 } & & $\mathbf{N}$ & $\mathbf{\%}$ \\
\hline F & 24 & 15 & 62.5 \\
\hline M & 36 & 11 & 30.6 \\
\hline Total & 60 & 26 & 43.3 \\
\hline \multicolumn{2}{|c|}{$\mathrm{X}^{2}$-test, P-value } & \multicolumn{2}{|c|}{$\mathrm{X}^{2}=4.75, \mathrm{P}=0.029$} \\
\hline
\end{tabular}

Table 2. Psychological test results in control group.

\begin{tabular}{|c|c|c|c|}
\hline \multirow{2}{*}{ Gender } & \multirow{2}{*}{ Total } & \multicolumn{2}{|c|}{ With neuroticism } \\
\cline { 3 - 4 } & & N & \% \\
\hline F & 31 & 6 & 19.4 \\
\hline M & 29 & 0 & 0 \\
\hline Total & 60 & 6 & 10 \\
\hline \multicolumn{2}{|c|}{ Fisher test } & \multicolumn{2}{c|}{$\mathrm{P}=0.0242$} \\
\hline
\end{tabular}

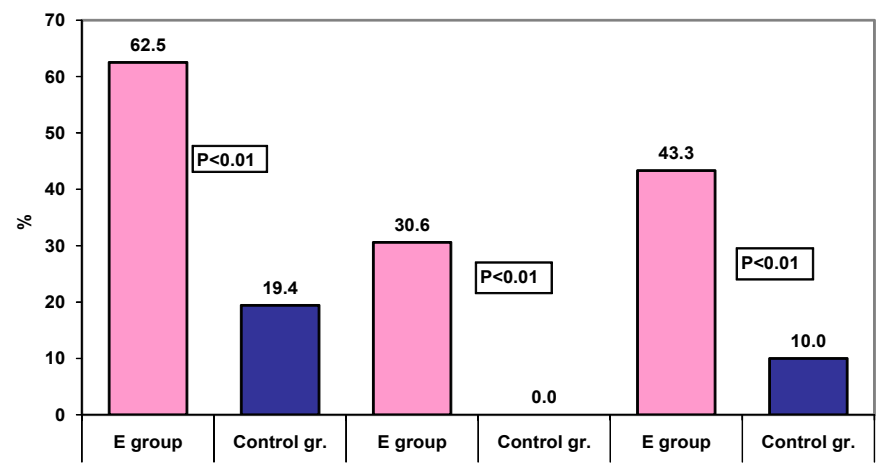

Figure 1. Structure of group with neuroticism according gender.
Table 3. Tendencies comparison according groups

\begin{tabular}{|c|c|c|c|}
\hline \multirow{2}{*}{ Tendencies } & Gr.E & Gr.K & \multirow{2}{*}{ P-value } \\
\cline { 2 - 4 } & $\mathbf{( \% )}$ & $\mathbf{( \% )}$ & \\
\hline Anxiosity & 55 & 23.3 & $\mathrm{P}=0.0008$ \\
\hline Depressivity & 26.7 & 6.7 & $\mathrm{P}=0.007$ \\
\hline Hipochondriasis & 36.7 & 6.7 & $\mathrm{P}=0.0001$ \\
\hline Phobia & 10 & 6.7 & $\mathrm{P}=0.743$ \\
\hline $\begin{array}{c}\text { Impulsive aggressive } \\
\text { tendencies }\end{array}$ & 21.7 & 1.7 & $\mathrm{P}=0.001$ \\
\hline
\end{tabular}

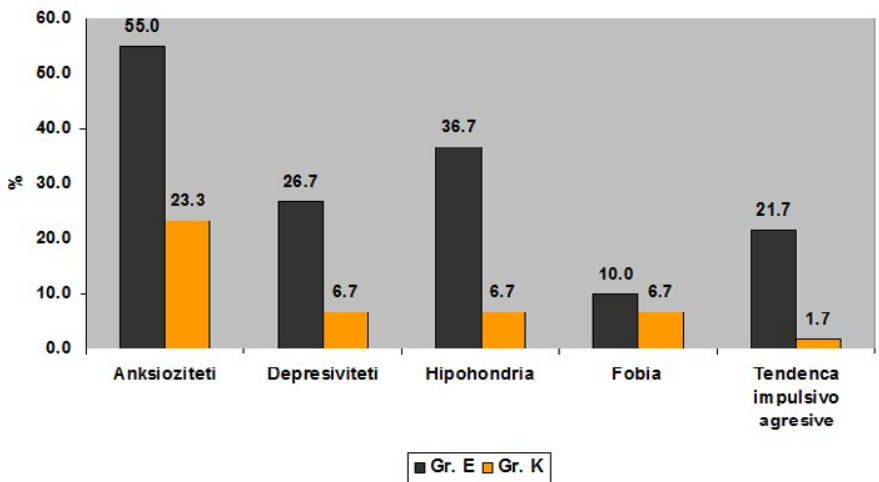

Figure 2. Tendencies comparison according groups.

Table 4. Correlation between tendencies and neuroticism in all patients with psoriasis

\begin{tabular}{|c|c|c|c|c|c|c|}
\hline \multirow{2}{*}{} & \multicolumn{2}{|c|}{$\begin{array}{c}\text { Gr. with } \\
\text { neuroticism }\end{array}$} & \multicolumn{2}{c|}{$\begin{array}{c}\text { Gr. without } \\
\text { neuroticism }\end{array}$} & \multicolumn{2}{c|}{ Total } \\
\cline { 2 - 7 } & $\mathbf{N}$ & $\mathbf{\%}$ & $\mathbf{N}$ & $\mathbf{\%}$ & $\mathbf{N}$ & $\%$ \\
\hline Total & 26 & 100 & 34 & 100 & 60 & 100 \\
\hline Anxiosity & 18 & 72 & 15 & 62.5 & 33 & 55 \\
\hline Depressivity & 16 & 64 & 0 & 0 & 16 & 26.7 \\
\hline Hipochondriasis & 18 & 72 & 4 & 16.7 & 22 & 36.7 \\
\hline Phobia & 6 & 24 & 0 & 0 & 6 & 10 \\
\hline $\begin{array}{c}\text { Impulsive aggressive } \\
\text { tendencies }\end{array}$ & 11 & 44 & 2 & 8.3 & 13 & 21.7 \\
\hline
\end{tabular}

\section{Correlation between tendencies and neuroticism in patients with psoriasis}

We observed a tendency of occurrence of anxiety, depressivity, hipochondriasis, phobia and impulsive aggressive tendencies in all patients with psoriasis group we detected signs of neuroticism (Table 4).

\section{Discussion}

Psoriasis is a chronic disease associated with experiencing emotional reactions with different intensity. Psoriasis does not endanger the patient's life but since the skin is exposed part of body many of them are not able to experience life pleasure. Consequently, patients with psoriasis most often suffer from depression, anxiety, other neurotic disorders and alcoholism [7-9].

In our paper we investigated the cases with psoriasis neuroticism. Anxiety was found in $55.0 \%$ of cases, whereas depressivity $26.7 \%$ occurred in the cases. Newly researches suggest that people with psoriasis have a greater risk of depression, anxiety, and suicidal thoughts. Compared with control group, patients with psoriasis had a $39 \%$ risk increase of clinical diagnosis of depressivity , 31\% anxiety and $44 \%$ suicidal thought [10]. Patients with psoriasis were 2.7 times more 
likely to be diagnosed with depression compared with patients without psoriasis [11].

A 2007 study of 514 Canadians with moderate to severe psoriasis was found that: $19 \%$ reported depression, $18 \%$ anxiety and $18 \%$ insomnia or other sleep disorders [12,13].

Comprehensive health care of psoriatic patients will involve mental health workers and trained dermatologists in psychosomatics and psychotherapy $[14,15]$.

\section{Conclusion}

It is with outmost importance that potential mental health disturbances are identified because they represent important comorbidities of psoriasis. Early detection and drug or psychotherapeutic treatment of those disturbances may help significantly toward the stabilization of the primary disease, psoriasis.

Future studies are necessary to determine the mechanisms by which psoriasis is associated with anxiety, depressivity or other neurotic disorders, as well as detection of potential strategies to prevent this potential harmful correlation, in patients with psoriasis.

\section{References}

1. Dostanic I (1993) Psoriasis. Beograd: Kosmos 6-65.

2. Cristophers E, Sterry W (1993) Psoriasis. Dermatology in general medicine. McgrawHill, New York 489-511.

3. Braun Falco O, Plewig G, Wolff Hh, Winkelmann RK (1991) Psoriasis. Dermatology. Springer-Verlag, Berlin 41737.
4. Walker C, Papadopoulos L (2005) Psychdermatology. Cambride University Press, New York 23-24.

5. Gupta MA, Gupta AK (1996) Psychodermatology: an update. J Am Acad Dermatol 34: $1030-1034$.

6. Christopher E, Mrowietz U (1999) Psoriasis. Fitzpatrick's Dermatology in General Medicine, (5thedtn), McGraw-Hill Medical, USA: 495-521.

7. Farber EM, Mall L (1994) Psoriasis and alcoholism. Cutis 53: 21-27.[Crossref]

8. Ramsey B, O Reagan M (1988) A survey of the social and psychological effects of psoriasis. Br J Dermatol 118: 195-201. [Crossref]

9. Root S, Keut G, Al-Abadie MSK (1994) The relationship between disease severity, disability and psychological distress in patients undergoing PUVA treatment for psoriasis. Dermatology 189: 234-237. [Crossref]

10. Kurd SK, Troxel AB, Crits-Christoph P, Gelfand JM (2010) The risk of depression, anxiety, and suicidality in patients with psoriasis: A population-based cohort study. Arch Dermatol 146: 891-895. [Crossref]

11. Jesitus J (2008) Depression and Psoriasis. Dermatology Times 29: 25-27.

12. Kirby B, Richards HL, Mason DL, Fortune DG, Main CJ, et al. (2008) Alcohol consumption and psychological distress in patients with psoriasis. Br J Dermatol 158: 138-140. [Crossref]

13. Idriss SZ, Kvedar JC, Watson AJ (2009) The role of online support communities: benefits of expanded social networks to patients with psoriasis. Arch Dermatol 145 46-51. [Crossref]

14. Folnegović malc V (1987) Uloga psihijatra u liječenju psorijaze. Psoriasis 24: 18-20.

15. Price ML, Mottahedin J, Mayo PR (1991) Can psychotherapy help patients with psoriasis. Clin Exp Dermatol 16: 114-117. [Crossref]

Copyright: $(\mathbb{C} 2015$ Blyta Y. This is an open-access article distributed under the terms of the Creative Commons Attribution License, which permits unrestricted use, distribution, and reproduction in any medium, provided the original author and source are credited. 